\title{
LA EXPOESÍA. UNA PERSPECTIVA ÉTICA Y POLÍTICA DE LOS PROCESOS ARTÍSTICOS CONTEMPORÁNEOS. EXPOÉTICAS ARGENTINAS Y SUS CONTEXTOS
}

\author{
Susana ROMANO SUED \\ Universidad Nacional de Córdoba - CONICET
}

\section{Observación preliminar}

bordar el universo de la creación poética contemporánea argentina en sus
contextos regionales, así como sus trayectos de experimentación y experiencia
-lo que hemos denominado aquí "expoesía"- con instrumentos teóricos adecuados, e insertarla en una historiografía que tome en consideración los efectos que en ella tiene el conjunto de los acontecimientos de la cultura, la política, la ética, reclama la revisión de las categorías de la teoría y la crítica para el acceso a dichos lenguajes, así como para su análisis e interpretación rigurosos. Luego, y habida cuenta del camino que ha tomado la civilización llamada global que hegemoniza el mundo con el poder tecno-digital, se hace patente y urgente la necesidad de una escucha y una mirada atentas frente al desfase y consiguiente estrechez de teorías al uso, enseñoreadas en los ámbitos académicos y paraacadémicos ${ }^{1}$. Es decir, se trata de reponer la relevancia de la eclipsada condición heterónoma de la literatura y el arte. Las improntas y rasgos intermediales y a la vez intergenéricos de las formas contemporáneas de la creación poética y artística, su circulación y multiplicación ad infinitum, ponen a prueba las terminologías consagradas del arte y la literatura, así como las de las disciplinas conexas, tornándolas en algunos casos obsoletas. De allí la necesidad de redefinir tanto el objeto de arte cuanto las categorías para su abordaje, incluso de un descubrimiento, un rescate de instrumentos epistemológicos nuevos, o bien ya existentes aunque no empleados en todo su potencial; y también, y muy especialmente, la necesidad de la invención.

\footnotetext{
${ }^{1}$ Véase Romano Sued (2010a). Asimismo, véanse Mukarovsky (1977) y Romano Sued (2001).
} 
Concierne revitalizar la dimensión heterónoma del universo artístico, retomando por ejemplo la articulación de la tríada norma-función-valor sistematizada por Mukarovsky a fin de cernir el fenómeno artístico desde la perspectiva de una estética semiológica de alcances socioculturales ${ }^{2}$. Estas maneras de operar con los legados más relevantes de la teoría estética protegen tanto de la infertilidad conceptual como del uso partidario de términos ${ }^{3}$. La revisión de escalas de valor de la experiencia estética expoética se impone pues como una necesidad de la teoría que se encuentra aún en estado exploratorio y fragmentario respecto de este objeto. Entiendo que, en un mundo del arte «post-Duchamp» (De Duve, 1998), no es necesario ni caer en una laxitud conceptual -como la de lo que denomino «críticos seriales» (Romano Sued, 2009)- ni en posiciones conservadoras aferradas a los viejos cánones categoriales. Jacques Rancière (2005) propone purgar la teoría estética de los ruidosos discursos sobre el fin del arte, de la historia y de la política (discursos que pueden subsumirse en el prefijo post- de efectos despolitizantes y conformistas que fueron arrolladores durante las últimas décadas del siglo XX). Así se recuperaría la condición trágica y poética de la cultura ${ }^{4}$. Es que la estética es eminentemente política, y esta condición no es sino la de la ética, dimensión que nos advierte acerca de que lo que no puede verse, ni mostrarse, como el horror que acompaña la tecnocivilización: el arte debe mostrarlo y la disciplina proponer el concepto para cernir la mostración, y para ello el psicoanálisis brinda un saber sobre la dimensión de lo real "innombrable", o nombrable desde la incompletud.

La expoesía como arte que opera en el campo de la representación no lo hace en la búsqueda de lo bello estético, de lo bonito. Más bien sacude en su demanda interpelante, inquieta al espectador porque lo arrastra al borde del vacío, desde donde muestra. Hace retroceder la espera de utilidad entretenedora, interrumpe el movimiento del rostro hacia lo que no turba, apunta al sacudón angustiante, y exige la detención y la pausa reflexiva. Va derechamente al cuerpo.

Lo que circula en los diversos formatos y soportes de la expoesía debería entonces ser abordado políticamente, esto es, restituyendo la eclipsada heteronomía de las prácticas de creación y sus obras resultantes. Dado que el arte anticipa y condensa los momentos cruciales de la historia humana, la materialidad de sus obras que desechan lo amable, la noia amnésica y holgazana, así como el monumento que es mudo, constituye

\footnotetext{
${ }^{2}$ Esta relevante contribución, no sólo es basamento de ulteriores teorías de la recepción al categorizar la obra de arte realizada como "objeto estético", rango que adquiere el "artefacto" u "obra cosa" en su materialidad de lenguaje al pasar por los procesos valorativos de receptores legos o especializados, del comentario y la crítica académica. "El arte como hecho semiológico" (1936) del autor checo constituye un fundamento indiscutible de la vinculación procesual entre la inmanencia de la obra y su trascendencia como objeto social. Véanse Mukarovsky (1977) y Romano Sued (2001).

${ }^{3}$ De Duve (1998) recupera la noción kantiana de lo sublime, como lo han hecho muchos autores contemporáneos.

${ }^{4}$ Véanse Grüner (2002) y Romano Sued (2003, 2005, 2010).
} 
una invitación a abrirse al susurro de la memoria del documento, que no es ya y no deja olvidar. Est/ética que teoriza entonces sobre un arte inscrito en sus condiciones históricas de producción y de recepción participante según he enunciado más arriba.

Al participar crecientemente de varios y diversos medios (medium) a la vez, las formas de creación poética contemporáneas muestran aspectos no canónicos entre los que debemos subrayar la complejidad y la multidimensionalidad. Ya puede hablarse de una tradición constante de entrelazamiento ininterrumpido entre distintos medios, técnicas y lenguajes en la literatura y las artes, así como de su simultánea apertura hacia contenidos sociales, políticos, económicos, religiosos, antropológicos y aun científicos. La penetración del mundo digital y cibernético en todos los dominios, desde los sentidos corporales hasta el activismo político manifiesto actualmente, sobre todo en las denominadas "redes sociales", entraña junto a la hipercomunicabilidad en tiempo real, una estetización de todos los ámbitos de la vida cotidiana, así como de una fascinación tecnolúdica de los usuarios-sujetos (Michaud, 2003; Bomheker, 2006; Romano Sued, 2003, 2006, 2008, 2010, 2011).

Este mismo hecho motiva el riesgo de la invención teórica, como he enunciado antes, lo cual legitima la creación de términos y conceptos correctamente fundamentados. Este desafío ha resultado en la creación del término, abarcativo aunque por cierto no totalizante, para cernir con mayor rigor el fenómeno poético enfocando su complejidad, multidimensionalidad, interdisciplinariedad e intermedialidad. De ello surge el vocablo expoesía ${ }^{5}$, al mismo tiempo término técnico y concepto, que empleamos en el marco de nuestras investigaciones. Este hallazgo permite nombrar y agrupar de manera operativa la enorme variedad de prácticas que conforman nuestro objeto de estudio, y también sortear las restricciones de la obsolescencia categorial ya mencionada.

\section{Expoesía, alcances actuales y potenciales de un término-concepto}

El prefijo ex-, cuya sinécdoque es $X$ - alberga un potencial semántico que condensa la pluralidad de dimensiones y atributos del objeto, potencial que a continuación consigno en algunas de sus numerosas significaciones.

\footnotetext{
${ }^{5}$ Que otorga su nombre tanto al sitio homónimo de Internet cuanto a diversos acontecimientos universitarios y poético-artísticos desplegados en el marco del programa Est/Éticas. En rigor, había sido ya utilizado a mediados de la década de 1970, en Brasil y en Alemania (Hohlfeldt, 1994), y más recientemente en diversos países, para designar bienales, festivales y otras manifestaciones poéticas experimentales.
} 
Ex-perimentación: aquí se incluyen las dimensiones visual, sonora, cinética, osmótica, géstica (todas ellas correspondientes al universo dramático); performática en su doble condición de universos dados y de potencia en el sentido de ex-ploración. La Ex-perimentación evoca asimismo el universo positivo de la ciencia empírica, la experiencia, también indisolublemente enlazada a las vicisitudes del sujeto en el presente de la creación, tanto del lado de quien produce cuanto del lado de quien recepta. La creación participa de la experiencia en tanto legataria de obras y constelaciones de obras del universo del arte que han sido vez procesadas y apropiadas por la obra que se está haciendo.

La nómina de sentidos que alberga el prefijo nos lleva también a la Ex-posición / Ex -hibición. A los verbos Ex-poner, Ex-hibir, Ex-citar, Ex-altar. Todos ellos conforman las condiciones de la multipolar dialéctica de la producción y la recepción. He anticipado el orden del drama: la expoesía conlleva el estatuto ostensivo de la puesta en escena, reclamando el mirar y el escuchar. También Ex-trañar, en el sentido de la Verfremdung brechtiana, procedimiento desalienante que permite captar la propia realidad en la alterización de una escena, de un tópico, de un contexto alejados del familiar entorno del sujeto receptor. Ex-tremar está incluido igualmente en el catálogo de sentidos, en tanto se llevan al límite y más allá del mismo los códigos convencionales.

En calidad de fin provisorio de los significados, el prefijo ex-indica la condición diferenciadora que la separa de otras formas, tradicionales, convencionales, que, aunque conviven con ella, pertenecen a una etapa dejada atrás. A todas estas derivaciones se añade la de Ex-portar, que se liga a su correlato Im-portar: es que la vinculación de las manifestaciones expoéticas con contextos regionales e intercontinentales es un factor fuertemente determinante en la producción vernácula ${ }^{6}$, estimulada por las operaciones de traducción.

\section{Antepasados filosóficos y poéticos. Hitos en una genealogía}

Mientras en su momento Stéphane Mallarmé había enunciado el estatuto del libro como tumba, como operación a la vez de intrusión de un objeto antes inexistente en el universo y de borradura del autor, Walter Benjamin (1988), años más tarde celebró que la palabra artística desbordara los límites del libro y su horizontalidad, y se desplazara

\footnotetext{
${ }^{6}$ Véase sobre todo cómo el gran campo de la poesía concreta, en primer lugar brasileña y luego alemana, compone el corredor de las operaciones de importación y exportación.
} 
por las verticales de la prensa escrita e integrara el neón nocturno de los carteles publicitarios, así como otras formas de composición de la letra en la urbe. Es lo que exaltaba en Dirección única como «plasticidad excéntrica». Inmerso y alucinado en París, Walter Benjamin estaba dando una respuesta algo diferente a la de Adorno -quizá por seguir confiando hasta cierto punto todavía en la preparación de una coyuntura revolucionaria-, con quien compartía la admiración por Mallarmé, en tanto había mostrado el camino para que la palabra artística saliera del ámbito convencional del libro. Benjamin descubría en el moldeado visual de la palabra un modo de desautonomización de la literatura, que aun cuando estuviera atravesada por las fuerzas regresivas del capitalismo, ofrecía al mismo tiempo una vía de su propia superación, precisamente a raíz de sus modos de apropiación de la técnica.

De acuerdo a sus formulaciones en Dirección única, las letras del alfabeto desasidas del formato libro, pululando en los letreros cual nube de langostas, eran a la vez la promesa de una nueva y excéntrica plasticidad (Benjamin, 1988: 38). Las vanguardias históricas, que pugnaban por la heteronomía, por el retorno de la radicación del arte en la vida cotidiana de la sociedad, asumiendo sus cambios y descubrimientos históricos y sociales, como el futurismo, el constructivismo, productivismo o la Bauhaus, asumieron como condición necesaria el "paisaje" de la novedad tecnológica desde posturas exaltatorias o utópicas, según los casos, siempre acopladas a la velocidad de transformación de ese nuevo paisaje.

Otras, en cambio, como Dadá y el surrealismo, incorporaron el sustrato técnico con una finalidad opuesta: liberar el mundo y las creaciones de su dimensión instrumental, un cuestionamiento dirigido certeramente a la concepción proteica de la burguesía que entendía toda innovación técnica como progreso. Cabe preguntarse aquí y analizar hasta qué punto a principios del siglo XX estaban dadas las condiciones de posibilidad de una tal liberación de esos rasgos instrumentales, y en qué medida desde entonces esas posibilidades se habrían ido cerrando progresivamente, con lo cual se habría cumplido la profecía negativa adorniana del mundo totalmente administrado que pondría en peligro el arte, sobre todo en su dimensión de autonomía.

Luego la reproductibilidad que planteaba enormes preocupaciones filosóficas y sociopolíticas a Walter Benjamin, llevada a sus últimas consecuencias, como ocurre de hecho con la cuasi total accesibilidad en la red, ofrece acaso una solución paradojal a la experiencia estética. La archicitada pérdida del aura ${ }^{7}$ causada por la reproducción indefinida e infinita de lo único, estaría al fin de cuentas compensada por el cambio en

\footnotetext{
${ }^{7}$ Comprendida sólo parcialmente puesto que se suele olvidar que tiene relación con la defectuosa reproductibilidad de los medios técnicos y sus soportes a la época en que el filósofo reflexionaba en su canónico ensayo.
} 
el estatuto del productor y el receptor del arte, de la literatura, de las obras híbridas; en cuanto al receptor, se trata de un sujeto que "ya" no es pasivo, pero que no se encontraría tampoco en la antigua situación confortable de la quietud estática del observador, ni en su casa, ni en el museo, ni en el teatro, si es que se desliza por la vía del trabajo de atender a las interpelaciones hacia su subjetividad. El libre acceso que promete y cumple la utopía tecnológica no es sin la demanda de entregar la libra de carne, la autoexplotación del esfuerzo subjetivo que se nos impone para lograr la sobrevivencia; el trabajo proactivo que impera en todos los ámbitos. Pero el alerta pregnante que atraviesa el arte en su potencia de mostración, anticipada o recordada, reclama abrir los ojos ante lo que no quiere ser visto o sentido, lo real ominoso, el vacío, y la incesante oferta de la elección subjetiva y responsable del sujeto contra el crimen del olvido, elección que lo devuelve a la comunidad ya no imaginada (Anderson, 1993), sino real.

La expoesía requiere y supone un receptor expoético. El rol interactivo y multisensorial que se asigna al receptor, se ejerce también por fuera de la esfera digital, en tanto se halla implicado en las performances y en las acciones-intervenciones que tienen lugar a menudo en espacios no sacralizados por los hábitos estéticos. La mixtura (inter y transmedial) de los medios o de los lugares implicados, interviene y modifica los hábitos de la lectura y la contemplación, no sólo al hibridar los sentidos, tanto el auditivo y el visual como todos los demás, sino requiriéndoles mucho más que antiguamente, para que el desciframiento de la obra sea principalmente un acto de participación. Lo que he llamado en otros contextos la mimesis y la simpraxis (Romano Sued, 1995: 21-23). Estos anticipos sismográficos de la expoesía, encuentran, a mi juicio, un correlato en el resurgimiento de la pasión política que se extiende como una epidemia por el planeta en una división bipolar paradójica, completando el ciclo de las acciones globalifóbicas, con resistencias notables que denuncian la marcha avariciosa del biocapitalismo global ${ }^{8}$.

La interactividad expoética, no está, por cierto, garantizada; más bien está prevista desde la autorialidad que prefigura un receptor. En el caso de que el contrato sea

\footnotetext{
${ }^{8}$ En las regiones del África árabe, y a través de las redes sociales y la telefonía móvil, se reclaman derechos libertarios y de consumo confortable de los cuales se priva a los ciudadanos por parte de regímenes dictatoriales; en los países del hemisterio norte "desarrollado" surge un combate apasionado anticapitalista global que podríamos denominar postconsumista. La expoesía, con sus modos creativos de intervención, recoge la consigna de Benjamin de politizar el arte, labrada en la alarma de la estetización fascista de la política. Asimismo, hace dos años, la enorme puesta en escena paranoica de la Gripe H1N1, que sirvió para desmenuzar socialidades y contactos entre personas presas del pánico por el probable contagio, significó pingües negocios para Big Farma y otros grandes laboratorios farmacológicos y ortopédicos que llegaron a un récord de ventas de vacunas, adquiridas por millones de unidades en países que procedieron a vacunaciones masivas, así como a imposiciones de usos de barbijos, desinfectantes, y autismos sociales.
} 
aceptado y concretado por un receptor, por un protagonista in fabula, de acuerdo con la postulación de Umberto Eco (1981), el hecho estético aurático o postaurático puede ser efectivamente realizado.

\section{Expoesía, arte de la transgresión, arte de la transición}

Si bien la transgresión expoética de los límites de la letra y de las artes en general se remonta a un siglo atrás, es sorprendente que todas estas creaciones poéticas "experimentales" en sentido amplio adscriban sus prácticas aún hoy y paradójicamente al sistema literario. Lo hacen por el hecho mismo de autodesignarse como "poesías", expandiéndose principalmente en el universo reticular de la Internet, donde abundan y abruman las creaciones de videopoemas, de poesía digital, así como todas las variantes que permiten las TICs para el empuje mimético de los usuarios.

Es decir, que la expoesía actual transita en una brecha tecnodigital que vuelve a poner en cuestión a la vez géneros y lenguajes, así como las ideas de poema, poesía, tradición, arte, artista, autor, autoría, lector, observador, espectador, creación, recepción y sujeto estético, entre otras.

\section{Nada existe fuera de lo tecnodigital}

A partir del giro tecnológico e icónico introducido por los desarrollos de los medios numéricos de información y comunicación (TICs) el universo virtual, el "éter", es el lugar donde se integran además las producciones y las acciones expoéticas provocando tanto una sobreabundancia como una homogeneización del continuum de la semiosfera (globosfera, etc.), en la cual se ha vuelto muy difícil distinguir entre lo que es o no poético, o artístico, ya que todo queda bajo la seductora capa de estetización generalizada.

En este contexto, retornamos a Walter Benjamin y a sus tesis concernientes a la reproductibilidad técnica (Benjamin, 1987) en tanto causante potencial de un cambio radical en el arte y en su función: dichas tesis cobran un nuevo sentido, más bien irónico. Puesto que la condición estética se sirve de un abanico de posibilidades inauditas pero devenidas cotidianas, fuente de nuevas competencias de recepción, subsume todos los recursos tecnológicos e incluye las producciones colectivas así como la "post-producción" (reutilizaciones, recontextualizaciones, ready mades, etc.). La letra se iconiza, y los datos visuales, acústicos y gestuales son literalizados. Dichas prácticas amplían el trabajo precedente de las vanguardias sobre la materialidad de palabra, esa herencia mallarmeana, así como el trabajo poético sobre la materialidad del sonido, 
reduciendo su complejidad de manera asombrosa. Los destinatarios, los receptores, se hallan sumergidos en un mundo de imágenes de toda naturaleza, visuales, auditivas, táctiles, osmóticas, gustativas, sin espacio intervalar alguno. Estos receptores-usuarios, cuyos cuerpos se adelgazan hasta cobrar la forma de un bit, deben responder permanentemente a las demandas estimulantes empleando competencias hasta hace poco inexistentes, aunque ya hay más de una generación entera de nativos en este ciberterritorio. El ejercicio mismo de la interactividad y del feedback que exige la recepción expoética de obras a menudo no definitivas o acabadas, impone renovaciones permanentes de los metabolismos receptivos.

Los sitios en la web, los portales, los blogs, las comunidades virtuales, las redes sociales funcionan como un espacio naturalizado de exposición de obras y de publicación de textos, sirviendo también para anunciar y organizar eventos, convocar a participaciones masivas en el campo de la política e incluso como vías de facilitación de contactos entre los creadores, el público y la crítica. Esta desmaterialización cuyo flujo tecnodigitalizado todo lo invade, es sin embargo contradicha en el campo de la realidad debido a las interrupciones que introduce la irrupción performática de los cuerpos.

A pesar de todo ello, las angustias creativas, las de influencia, o la aceptación de las genealogías, la afirmación de la propia originalidad, no destierran a los creadores de expoesía, expoetas, lo cual se verifica en la multiplicación exponencial de las producciones y las acciones. En este contexto, luego, espigar la hierba y distinguir la buena de la mala resulta una tarea difícil. Hoy en día, la relación entre receptor, obra y artista, ha sufrido una alteración fóbica, por así decir, pues en la dimensión técnicoglobal no existe ya el contacto directo exclusivo, ni siquiera con la obra, mediatizada inexorablemente por la interfaz de los diversos objetos dígito-tecnológicos. Ordenadores personales, note y netbooks, iPhones, iPads, celulares sofisticados e inminentes encarnaciones de partículas cibernéticas en los órganos que recibirán señales directas al cuerpo sin mediador alguno.

\section{Expoesía argentina en contextos latinoamericanos. Genealogías, hitos, evidencias}

Ese es precisamente el contexto mundial en el que emerge la expoesía latinoamericana y la argentina, con rasgos semejantes, es decir, que se configura también con elementos icónicos, volumétricos, cinéticos, acústicos, gestuales, y yuxtapone asimismo lenguas y lenguajes integrando el cuerpo del mismo creadorperformer en tanto que medio inserto en su objeto, y hasta disuelto en él ${ }^{9}$.

\footnotetext{
9 Las formas de la producción poética latinoamericana y argentina de los años recientes, la contemporánea, revelan una multiplicidad de voces tanto en el aspecto formal como temático: la poesía
} 
En la Argentina, la expoesía que se practica actualmente puede decirse que se constituyó como tal a comienzos de la década de 1980. Pero se enraíza sin duda en una genealogía ya secular, a la vez literaria y artística: la de las diferentes vanguardias históricas europeas (Bürger, 1997; Schwartz, 1991). En cualquier caso, los practicantes actuales de la expoesía argentina se refieren a tres precursores: Oliverio Girondo (18911967), Xul Solar (1887-1963) y Edgardo Antonio Vigo (1928-1997).

Durante sus sendos años juveniles, Girondo, Solar y Vigo vivieron en Europa, donde establecieron lazos con otros vanguardistas ${ }^{10}$. En la primera mitad del siglo XX, los grandes movimientos de la modernidad encontraron rápidamente sus ecos en la Argentina, en especial en Buenos Aires, capital federal y centro cultural principal (visible), no solamente del país sino de toda la América del Sur hispanohablante de la época. Recordemos brevemente el paso de Marcel Duchamp por Buenos Aires en 1917, por cierto un hecho anecdótico pero muy revelador de la mirada porteña, puesta principalmente en el ombligo parisino.

El ultraísmo, de inspiración futurista, fundado en Madrid en 1918, fue muy activo en la Argentina desde comienzo de la década de 1920, especialmente alentado por las revistas Prisma, Proa y Nosotros, que impulsaban poetas de primera línea como Jorge Luis Borges y Oliverio Girondo. La última obra de éste, la más influyente de las suyas, En la masmédula, data de 1957. Su influencia actual sobre las manipulaciones del lenguaje escrito y oral sigue siendo poderosa.

El surrealismo, profundamente marcado en el país por la obra propia y de traducción de Aldo Pellegrini, atrajo a innumerables adherentes. Sin embargo, y aunque un tanto marginal al movimiento "oficial”, en Argentina nadie encarna mejor el espíritu surrealista que Xul Solar, pintor, esotérico e inventor de lenguas artifíciales y de escrituras jeroglíficas pictóricas. Estos precursores fascinaron a los practicantes de la expoesía contemporánea

neobarroca se encuentra con enfoques performativos, el minimanlismo de lo cotidiano se hibrida con experiencias del campo político, las creaciones poéticas de cuño neorromántico se ensamblan con hipertextualidades actuales. Las fuentes-yacimientos, las canteras ilimitadas de figuras de la poesía del continente, como Borges, Lispector, Neruda, Sor Juana, Alejandra Pizarnik, Lezama Lima, Nicolás Guillén, Gabriela Mistral, entre otras, se proyectan en las reutilizaciones visualizadas, en términos paródicos y grotescos. Estos materiales son ensamblados con recursos formales que entroncan con la tradición medieval. En la búsqueda de los intersticios, de lo híbrido, de la topografía latinoamericana, del orden genérico, de las literaturas generacionales se llega a expresiones queer, a manifestaciones clásicas, que hacen estallar rutinas y reclaman la escucha, la mirada, el gesto y todos los sentidos a la vez. La poesía latinoamericana tras la metabolización de los legados vanguardistas y el serenamiento del llamado boom, deviene expoesía con los rasgos que la tipifican, tanto en Argentina como en Bolivia, Chile, Perú, Uruguay y otros países al norte del cono sur, en la dialéctica de lo otro y de lo mismo que plantea el mundo digital entre las metrópolis y las periferias.

${ }^{10}$ Cumpliendo así con el acostumbrado ritual de la experiencia de los artistas e intelectuales argentinos desde el comienzo de la patria. 
La expoesía. Una perspectiva ética y política de los procesos artísticos...

-expoetas los nombraremos en adelante- debido al carácter eminentemente transliterario de sus obras.

En 1954, en La Plata, capital de la provincia de Buenos Aires, Edgardo Antonio Vigo comienza a ejercer su actividad multiforme en la xilografía, en la poesía concreta, en el arte de recuperación de desechos y espacios, en la instalación, en el arte correo, etc. Esta figura mayor de la creación argentina del siglo XX funda, en 1961, la revista Diagonal Cero y desarrolla hasta su muerte una intensa actividad creativa y teórica que habrá de proyectar una enorme influencia en la producción argentina hasta la actualidad $\left(\right.$ Davis, 2007) ${ }^{11}$.

El situacionismo, la poesía concreta brasileña y el arte conceptual cobran fuerza en particular en la ciudad de Rosario, verificándose el habitual «eje cerealero portuario» (Romano Sued, 2009) del que vienen importados y adoptados en el país. El Instituto Di Tella de Buenos Aires (1958-1970), una fundación dedicada a todas las investigaciones de vanguardia del momento, organiza happenings, instalaciones y manifestaciones cercanas a la poesía sonora. En la década de 1970 surge una corriente emparentada con el neobarroco caribeño y latinoamericano. Sus protagonistas son, entre otros, Emeterio Cerro y Néstor Perlongher, ya fallecidos, Arturo Carrera (Pringles, Buenos Aires) y Héctor Píccoli (Rosario, Santa Fe), quienes constituyen figuras siempre presentes en el panorama poético argentino, estando algunas de sus creaciones integradas en los nuevos medios así como en las manifestaciones públicas de la expoesía.

Para la misma época aparece Xul / signo nuevo y viejo (llamada así en homenaje a Xul Solar), breve pero densa revista creada por Jorge Santiago Perednik y un grupo muy activo de expoetas que presenta ya todas las características de la expoesía actual con excepción, claro, de las asociadas estrictamente a las poéticas tecnológicas ulteriores (Romano Sued, 2008). Xul ya había reunido entonces a creadores (cuya actividad continúa hasta el presente) que se han convertido en referencias definitivas e indiscutibles para los jóvenes expoetas. De todos modos, y como ha sido dicho, es durante la década de 1980 que dichas prácticas devienen predominantes. Los propios creadores, así como los investigadores -que en numerosos casos confluyen en las mismas personas-, afirman de manera unánime (Longoni, 2007) que esta amplia difusión depende estrechamente de las transformaciones económicas, políticas y tecnológicas que atraviesan la Argentina y el mundo durante esos años. La Internet y la

\footnotetext{
${ }^{11}$ En la década de 1960 en Córdoba, periferia del porteñocentrismo, interviene Jorge Bonino, con sus lenguas, hablas y lenguajes, «aclarando ciertas dudas», como denominaba a su propia intrusión de códigos fuera de discurso, incapturable por la racionalidad convencional de la crítica serial. Logró llevar su enseñanza performática expoética al Instituto DiTella de Buenos Aires, albergue de todo rupturismo radical en las artes. Cfr. http://www.revistalamasmedula.com.ar/nro3/bardos.htm (última consulta, 6-122011).
} 
globalización son los acontecimientos más comúnmente citados, así como las raíces políticas contestatarias de los grupos expoéticos que se desarrollaron a partir de la recuperación de la democracia, tras la caída de la dictadura cívico militar en 1983.

Sería imposible detallar aquí en forma exhaustiva la profusión de autores individuales y de colectivos poéticos, o mejor dicho expoéticos, que circulan en la escena argentina actual. Entre los colectivos mencionaré algunos que resultan ejemplarmente significativos para ilustrar los rasgos que he venido señalando hasta aquí. El Grupo PARA, de Misiones; el M. A. R., de Entre Ríos; el Proto-Copyleft L, de Córdoba; Activa Memoria, del Chaco; Woki Toki, de Santa Fe; y los Iconoclasistas de Buenos Aires. Destaco especialmente la revista ramona puesto que ha consagrado dossiers indispensables para nuestro objeto de indagación y reflexión.

El sitio www.expoesia.com en su rúbrica "Xenografías" ofrece un muestreo significativo de obras de autores actuales destacados, como Roberto Cignoni, Mirta Dermisache, Fernando García Delgado, Favio Doctorovich, Roberto Elía, Lilian Escobar, Silvana Franzetti, Belén Gache, Jorge Garnica, Andrea Gagliardi, Ladislao Pablo Gyori, Jorge Lépore, Jorge de Luxán Gutiérrez, Jorge Macchi, Karina Macció, Hilda Paz, Santiago Perednik, Pazos, Juan Carlos Romero, Claudia del Río, Javier Robledo, Bernardo Schiavetta, Roberto Scheines, Javier Sobrino, Alejandro Hornton y Horacio Zabala.

En la ciudad de Córdoba existe desde la década de 1990 lo que podríamos llamar un movimiento expoético que pugna por visibilizarse a partir de circuitos marginales, no oficiales, y que han provocado expectación a partir de instancias institucionales. Las lecturas en alta voz combinadas con performances, la puesta a prueba de trabajos en proceso (work in progress), las videoproyecciones, intervenciones urbanas, instalaciones, en ámbitos que el municipio cordobés comenzó a disponer para alojar las manifestaciones alternativas, introdujeron una patrimonialización de las creaciones que han fracturado los conceptos estereotipados sobre poesía ${ }^{12}$. Ferias de editoriales y publicaciones alternativas, tecnofestivales digitales de gran convocatoria de público,

12 La apertura sistemática del Centro España Córdoba, cuyos equipos de gestión han trabajado mancomunadamente para promover, auspiciar y hacer visibles este tipo de creaciones, así como la oferta de espacios de realización activa de expoetas, como el sitio CASA 13 del Paseo de las Artes, constituyen un hito relevante para la legitimación de la expoesía, habilitando su inserción como objeto de investigación universitaria. A título de ejemplo, destaco la obra en continuo desarrollo de Raúl Lafuret Pereyra, frecuentador expoético de múltiples lenguajes a partir de su plataforma composicional de la música y autor de numerosas obras individuales y colectivas, e integrante de diversos colectivos, como Ambos Mundos y El Cíclope, entre muchos otros. Lafuret indaga entre una sumatoria de trabajos sonoros, literarios y visuales que se avecinen a una obra integral, teniendo en cuenta la forma, las tensiones y distensiones y, sobre todo, un modo de forjar un trabajo multimedial, siempre regidos por el pluralismo sonoro, por la música electroacústica y una orquestación académica. Véanse los sitios http://www.ccec.org.ar/2008/10/los-beneficios-de-la-vanidad/ y http://www.expoesia.com (última consulta, 6-12-2011). 
principalmente jóvenes, sistematizaciones en mediatecas y otras actividades programáticas afines de las instituciones, han convivido con la fuerza retrógrada de las historiografías oficiales de los claustros académicos hasta comienzos del siglo XXI, momento en el cual iniciamos la actividad de integración de estos objetos a nuestras investigaciones estéticas.

Francine Masiello introduce un aporte singular en el discurso crítico, al considerar que, más allá de los entusiasmos por los fragmentos que la cultura tecnodigital provoca, habría un arte de la transición, donde la palabra poética opera como resistente. La crítica, la teoría, deben acompañar esta resistencia, que no es sino una negativa ante la seducción de la lógica del mercado, del capitalismo tardío, que necesita la disgregación descentrada y autorreferencial, despojada de toda potencia política, tal como los discursos posmodernos la prefieren en su programa devastador (Masiello, 2001). Curiosamente, la desmaterialización de la vida nos sitúa, medio siglo después del pionero libro de Umberto Eco, en el reino de la «obra abierta» (Eco, 1979). El enigma de la experiencia aurática sigue sin embargo vigente. Irónicamente, ella abre una ventana, un horizonte, en medio mismo de la maquinaria del mercado, que redobla permanentemente los embates del poder, automatizado e idiota, pero eficaz, al que socavan las poéticas político tecnológicas -como las denomina acertadamente Claudia Kozak-, interviniendo e interrumpiendo la fetichización y conversión en mercancía de todo lo que cae bajo su dominio.

\section{Interrogantes (in)conclusivos. Expoesía en la alternancia entre el olvido pesimista y la materialización ética}

En este punto y a manera de síntesis conclusiva formulo dos preguntas, dilemáticas, y hasta oximorónicas:

1. La expoesía ¿no sería, pues, la expresión misma de la cultura digital y de su reproductibilidad sin fin en cumplimiento de la profecía pesimista de Walter Benjamin?

2. La expoesía, en su dimensión material de condición performática y de activismos sociopolíticos, ¿no será la práctica de resistencia a toda virtualización global, a toda homogeneización estetizante de la caricia digital, a todo conformismo nirvanático de la vida lúdica - la «nuda vida» aclamada por Giorgio Agamben (2003) - y apolítica, propuesta por el biocapitalismo tecnoglobal? 
116 Tropelías. Revista de Teoría de la Literatura y Literatura Comparada, 18 (2012)

Susana Romano Sued

\section{Referencias bibliográficas}

ADORNO, T. W. (2004): Teoría estética. Madrid, Akal.

AGAMBEN G. (2003): Homo Sacer, el poder soberano y la nuda vida I. Valencia, Pretextos.

ANDERSON, B. (1993): Comunidades imaginadas. Reflexiones sobre el origen y la difusión del nacionalismo. México, Fondo de Cultura Económica.

BENJAMIN, W. (1987): Discursos Interrumpidos. Taurus, Madrid. (1988): Dirección única. Madrid, Alfaguara.

BERTI, A. (2007): "La crisis del soporte: la falsificación en la en la época de la reproductibilidad técnica", en Actas de las II Jornadas Internacionales de Expoesia y Experimentación. Córdoba, Epoké, http://www.expoesia.com/j07 berti.html (última consulta, 6-12-2011).

BOMHEKER, M. (2007): "Ética y Estética", en Actas de las II Jornadas Internacionales de Expoesia y Experimentación. Córdoba, Epoké, http://www.expoesia.com/j07_bomheker.html (última consulta, 6-12-2011).

BURGER, P., SARMIENTO GARCÍA, J. H., \& PIÑÓN, H. (1997): Teoría de la vanguardia. Barcelona, Península.

DAVIS, F. (2007): "Reencontrarse con Vigo", ramona 76, pp. 11-20.

DE DUVE, T. (1998): Kant After Duchamp. Cambridge, MIT Press.

ECO, U. (1979): Obra abierta. Barcelona, Ariel.

(1981): Lector in fabula: la cooperación interpretativa en el texto narrativo. Barcelona, Lumen.

GRÜNER, E. (2002): El fin de las pequeñas historias. Buenos Aires, Paidós.

HOHLFELDT, A. (1994): Pelas veredas da literatura brasileira. Porto Alegre, Edipurcs.

KOZAK, C. (2007): “Construcción y exploración de lenguajes. Del poema proceso a la tecnopoesía", en Actas de las II Jornadas Internacionales de Expoesia y Experimentación. Córdoba, Epoké, http://www.expoesia.com/j07_kozak.html (última consulta, 6-12-2011).

LONGONI, A. (2007): "Encrucijadas del arte activista en la Argentina", ramona 74, pp. $31-43$.

MASIELLO, F. (2001): El arte de la transición. Buenos Aires, Norma.

MICHAUD, Y. (2003): L'Art à l'état gazeux. Essai sur le triomphe de l'esthétique. París, Stock.

MUKAROVSKY, J. (1977): Escritos de estética y semiótica del arte. Barcelona, G. Gili.

RANCIÈRE, J. (2005): Malaise dans l’Esthétique. París, Galilée. 
La expoesía. Una perspectiva ética y política de los procesos artísticos...

ROMANO SUED, S. (1995): La diáspora de la escritura. Una poética de la traducción poética. Córdoba, Alfa.

— (2001): Jan Mukarovsky y la fundación de una nueva estética. Córdoba, Epoké. (2003): "Estética y subjetividad. Metamorfosis en la era tecnodigital", en Travesías. Estética. Poética. Traducción. Foco Cultural Ediciones, Córdoba.

- (2005): "La panlingua intertextual de Xul Digital", en E. Livon-Grosman, ed., 5+5. Boston, Boston Collage, http://www.bc.edu/research/xul/5+5/romano.htm (última consulta, 6-12-2011).

- (2006a): “Utilización social y política del arte en el mundo Contemporáneo", en Actas de las I Jornadas Internacionales de Expoesia y Experimentación. Córdoba, Epoké, http://www.expoesia.com/jornadas_06.html (última consulta, 6-12-2011). (2006b): "Intermedialidades: arte y poesía en movimiento", en Actas de las I Jornadas Internacionales de Expoesia y Experimentación. Córdoba, Epoké. http://www.expoesia.com/j06_romano.html (última consulta, 6-12-2011).

_ (2009): "Ética y estética: críticos seriales", en El hilo de la fábula, 8 y 9, pp. 144149.

- (2010a): "Legalidad y legitimidad de los discursos académicos y paraacadémicos de la Argentina", Anuario de la Universidad Nacional de la Pampa, pp. 13-26.

— (2010b): " $L$ ' «expoesie» argentine et ses contextes. Formes transgénériques de la poésie experimentale actuelle”, Formules, 14, pp. 261-269.

- (2011): "Cuerpos y Arte: enigmas en las obras muertas", Enigmas del Cuerpo. Revista de Psicoanálisis, 2, pp. 66-72.

SCHWARTZ, J. (1991): Las Vanguardias latinoamericanas: textos programáticos y críticos. Madrid, Cátedra. 